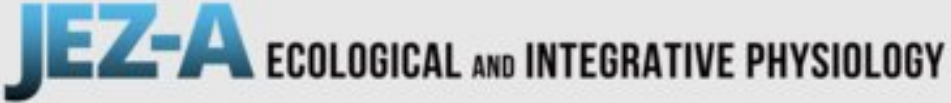

\section{Embryotoxicity characterization of the flame retardant Tris(1-chloro-2-propyl)phosphate (TCPP) in the invertebrate chordates Ciona intestinalis}

\begin{tabular}{|r|l|}
\hline Journal: & Journal of Experimental Zoology Part A \\
\hline Manuscript ID & Draft \\
\hline Wiley - Manuscript type: & Research Paper \\
\hline Date Submitted by the \\
Author: & n/a \\
\hline Complete List of Authors: & $\begin{array}{l}\text { MERCURIO, SILVIA; Università degli Studi di Milano, Department of } \\
\text { Environmental Science and Policy } \\
\text { Messinetti, Silvia; Università degli Studi di Milano, Department of } \\
\text { Environmental Science and Policy } \\
\text { Manenti, Raoul; Università degli Studi di Milano, Department of } \\
\text { Environmental Science and Policy } \\
\text { Ficetola, Francesco; Università degli Studi di Milano, Department of } \\
\text { Environmental Science and Policy } \\
\text { Pennati, Roberta; Università degli Studi di Milano, Department of } \\
\text { Environmental Science and Policy }\end{array}$ \\
\hline Keywords: & $\begin{array}{l}\text { Marine invertebrate, neural development, nervous system, muscle, } \\
\text { myogenesis, chlorinated organophosphorus flame retardant }\end{array}$ \\
\hline
\end{tabular}


1 Embryotoxicity characterization of the flame retardant Tris(1-chloro-2-propyl)phosphate 2 (TCPP) in the invertebrate chordates Ciona intestinalis

4 Running title: flame retardant on ascidian development

Mercurio Silvia $^{1, *}$, Messinetti Silvia ${ }^{1,2}$, Manenti Raoul ${ }^{1}$, Ficetola Gentile Ficetola ${ }^{1}$, Pennati Roberta $^{1}$ 7

$8{ }^{1}$ Università degli Studi di Milano, Department of Environmental Science and Policy, via Celoria 2, 920133 Milan, Italy.

102 Present address: Chemservice s.r.l., via F.lli Beltrami 15, 20026 Novate Milanese (MI), Italy

$11 *$ Corresponding author: sil.mercurio@gmail.com

13 Abstract

Tris(1-chloro-2-propyl)phosphate (TCPP) is the most common chlorinated organophosphorus flame retardant in seawater. Due to its chemical features and abundance, TCPP has been classified as high hazard and restrictions of use have been set in multiple countries. Despite TCPP is highly present in the marine environment, only few studies have explored TCPP impact on the development of marine invertebrates. Ascidians are important invertebrate members of benthic marine communities and reliable model systems for ecotoxicological research. The aim of this study was to assessed the adverse effects of TCPP exposure on the embryogenesis of the ascidian Ciona intestinalis. Our results showed that this pollutant affected both muscles and nervous system development. Malformations appeared similar to those reported in other animal models for other flame retardants, suggesting that these molecules could share a common mechanism of action and induce mixture effect when simultaneously present in aquatic environment even at sub-teratogenic concentrations.

\section{Keywords}

Marine invertebrate, neural development, nervous system, muscle, myogenesis, chlorinated organophosphorus flame retardant. 


\section{1. Introduction}

2 Environmental pollution is one of the main causes of the ongoing loss of biodiversity (Cuvillier-Hot

3 \& Lenoir, 2020). Anthropogenic contaminants are indeed widespread in all ecosystems, threatening

4 animal health. Among these pollutants, plastic additives and organophosphorus flame retardants

5 (OPFRs) are currently raising increasing concern (Wang et al., 2020).

6 Tris(1-chloro-2-propyl)phosphate (TCPP) is the most abundant chlorinated OPFRs detected in 7 seawater (Ji et al., 2020; Sundkvist et al., 2010; Wang et al., 2020). It is a non-volatile colorless liquid 8 added, but not chemically bonded, to polymers, thus prone to migrate to the surrounding environment. 9 TCPP is classified as not readily biodegradable, with a relative high solubility in water (Bekele et al., 10 2019; Truong et al., 2017; X. Wang et al., 2020). It represents the $80 \%$ of chlorinated flame retardants 11 used in Europe and it is regarded as the most important OPFRs in terms of volume (Ekpe et al., 2020). 12 Due to all these features, TCPP has been classified as high hazard by the U.S. Environmental 13 Protection Agency (EPA) and restrictions of use have been set in western countries (Ji et al., 2020; 14 X. Wang et al., 2020). Though, TCPP is highly present in marine environment: even if its 15 concentrations are very variable, ranging from $35.6 \mathrm{ng} / \mathrm{l}$ in the Yellow Sea (Zhong et al., 2020) to $165.77 \mathrm{ng} / \mathrm{l}$ in North Atlantic and Artic Ocean (Li et al., 2017), TCPP displays a 100\% detection rate in 17 seawater (Li et al., 2017; X. Wang et al., 2020; Zhong et al., 2020).

18 In the last years, an increasing number of research has explored TCPP adverse effects on human and 19 animal health. However, these studies were performed mainly in vitro or on vertebrate models. It has 20 been demonstrated that TCPP induced a decrease of cell viability, an increase of reactive oxygen 21 species (ROS) production and changes in genes expression in different cellular phenotypes (Du et al., 22 2019; Ji et al., 2020; Shi et al., 2019; Wang et al., 2020; Zhu et al., 2018). During zebrafish 23 development, exposure to TCPP concentrations higher than $100 \mu \mathrm{M}$ did not cause evident 24 morphological malformations but alterations in swimming behavior were observed (Dishaw et al., 25 2014; Noyes et al., 2015). Developmental toxicity was instead reported in chicken embryos which 26 showed a reduced tarsus length and a delay of pipping after in ovo exposure to $>10 \mu \mathrm{g} / \mathrm{g}$ TCPP (Farhat 27 et al., 2013).

28 Conversely, only limited research has focused on invertebrates. In the freshwater species Daphnia 29 magna, the median lethal concentration $\left(\mathrm{LC}_{50}\right)$ resulted $81 \mathrm{mg} / \mathrm{l}$ (Cristale et al., 2013) while in 30 Caenorhabditis elegans was up to $857 \mathrm{mg} / \mathrm{l}$ (Xu et al., 2016). A deeper investigation on TCPP effects on marine species was only performed on Mytilus galloprovincialis, revealing that exposure to 100 $32 \mathrm{nmol} / 1$ TCPP for 42 days enhanced ROS production, apoptosis and oxidative stress (Wu et al., 2018; $33 \mathrm{Xu}$ et al., 2016). Lack of information on marine invertebrates appears particularly worrying as these 
1 animals include the majority of species and play key roles in all ecosystems (Cuvillier-Hot \& Lenoir, 2 2020).

3 In this respect, the present study aims to investigate the effects of TCPP exposure on the embryonic 4 development of ascidians. Ascidians are invertebrate chordates belonging to tunicates (Delsuc et al., 5 2006). These organisms are important members of the marine benthic community, contributing to 6 increase ecosystem biodiversity through the colonization of different natural and artificial substrates 7 (Sepúlveda et al., 2014). In the last years, ascidians have been recognized as reliable model systems 8 for ecotoxicological research, thanks to their wide distribution and ecology as well as for their rapid 9 embryonic development, and high production of gametes (Eliso et al., 2020; Messinetti et al., 2018; 10 Messinetti, Mercurio, \& Pennati, 2019). In particular, we employed Ciona intestinalis as model 11 organism and focused on TCPP adverse effects on embryonic development, i.e. one of the most 12 sensitive stages of animal lifecycle. Our work added important toxicological information about TCPP 13 in marine environment and showed TCPP developmental effect on muscles and nervous system. 14 These results arised concerns about OPFRs additive effects on aquatic organisms, which could 15 seriously threaten ecosystem health.

2. Materials and methods

$18 \quad$ 2.1. Animals and chemicals

19 Adults of Ciona intestinalis were collected by the fishing service of the Station Biologique de Roscoff 20 (France). Animals were maintained in aquaria filled with seawater. Temperature was fixed at $18 \pm 1^{\circ} \mathrm{C}$ 21 and constant light condition was preferred.

22 All the experimental procedures were performed at $18 \pm 1^{\circ} \mathrm{C}$. For each experiment, three animals were 23 sacrificed. Gametes were obtained by dissection, and cross-fertilization was performed in glass Petri 24 dishes (diameter $4 \mathrm{~cm}$ ).

25 TCPP (MW = 327.57) was purchased from Sigma (Milan, Italy). A stock solution of $100 \mathrm{mg} / \mathrm{ml}$ was 26 made in dimethyl sulfoxide (DMSO; Sigma, Milan, Italy) and then diluted in filtered seawater (FSW) 27 to reach the final test concentrations. A solution of $0.1 \%$ DMSO in FSW was used as solvent control 28 each time.

\section{2.2. TCPP exposure during embryogenesis}

30 About 50 C. intestinalis embryos at 2-cells stage were transferred in Petri dishes filled with $10 \mathrm{ml}$ of 31 TCPP solutions and reared until larva stage ( $18 \mathrm{hpf}$ ) (Hotta et al., 2007). After preliminary trials, 32 experiments were performed at the following concentrations: $6 \mu \mathrm{g} / \mathrm{ml}, 12.5 \mu \mathrm{g} / \mathrm{ml}, 25 \mu \mathrm{g} / \mathrm{ml}, 35$ $\mu \mathrm{g} / \mathrm{ml}, 50 \mu \mathrm{g} / \mathrm{ml}, 65 \mu \mathrm{g} / \mathrm{ml}, 75 \mu \mathrm{g} / \mathrm{ml}$ and $100 \mu \mathrm{g} / \mathrm{ml}$. Two control groups were set every time: control 
1 embryos maintained in FSW (CO) and solvent control reared in 0.1\% DMSO in FSW (DMSO). Each experiment was repeated three times and considered reliable only if $80 \%$ of $\mathrm{CO}$ embryos hatched.

3 When $\mathrm{CO}$ embryos reached larval stage, all samples were fixed in $4 \%$ paraformaldehyde, $0.5 \mathrm{M} \mathrm{NaCl}$,

$4 \quad$ 0.1 M 3-(N-morpholino)propanesulfonic acid (MOPS fixative; $\mathrm{pH}$ 7.5) for $90 \mathrm{~min}$, washed in PBS 5 with $0.1 \%$ Tween-20 (PBT) and examined under a microscope. The number of normal, malformed 6 and dead larvae was annotated, and the corresponding percentage was calculated. Then, specimens 7 were dehydrated in ethanol series $(30 \% ; 50 \%$ and $70 \%)$ and stored at $-20^{\circ} \mathrm{C}$ for further analyses.

$8 \quad$ 2.3. Microscopy

9 Fixed larvae of $C$. intestinalis were processed based on standard light microscopy technique 10 (Messinetti, Mercurio, Scarì, et al., 2019). After dehydration, samples were stained in Ponceau Red 11 and embedded in Technovit resin (Heraeus Kulzer, Werheim, Germany) according to manufacturer's 12 guideline. Longitudinal sections $(5 \mu \mathrm{m})$ were cut with microtome and stain with hematoxylin and 13 eosin. Samples were observed under a Leica microscope and photographed using Leica DFC-320-C 14 camera.

\section{$15 \quad$ 2.4. Immunohistochemistry}

16 Standard protocol for immunostaining of neural fibers was performed (Messinetti, Mercurio, \& 17 Pennati, 2019). After rehydration, larvae were permeabilized for $45 \mathrm{~min}$ in PBTT (PBS; 0.1\% 18 Tween-20; $0.25 \%$ Triton X-100) and incubated for 2 hours in 50\% PBT/50\% inactivated goat serum. 19 Then, samples were incubated overnight at $4^{\circ} \mathrm{C}$ with anti- $\beta$-tubulin monoclonal antibody developed 20 in mouse (clone 2-28-33; Sigma, Milan, Italy), diluted 1:500 in PBT. Samples were washed in PBT, 21 blocked in 1\% bovine serum albumin in PBT for 2 hours at room temperature and finally incubated 22 overnight with secondary antibody (Alexa Fluor 488 anti-mouse IgG, Sigma, Milan, Italy), diluted 23 1:800 in PBT at $4^{\circ} \mathrm{C}$. After washes in PBT, larvae were mounted in 1, 4-diazabicyclo [2,2,2] octane 24 on microscope slides and examined at confocal laser scanning microscope.

\section{$25 \quad$ 2.5. Whole mount in situ hybridization}

26 To explore TCPP effects on $C$. intestinalis neural development, in situ hybridizations with 27 digoxigenin riboprobes were performed as previously described (Messinetti, Mercurio, \& Pennati, 28 2019). Briefly, after rehydration, larvae were permeabilised with $4 \mu \mathrm{g} / \mathrm{ml}$ proteinase $\mathrm{K}$ and post-fixed 29 in MOPS fixative. Prehybridization was carried out in $50 \%$ formamide, $5 \times \mathrm{SSC}, 100 \mu \mathrm{g} / \mathrm{ml}$ yeast RNA, $50 \mu \mathrm{g} / \mathrm{ml}$ heparin, $0.1 \%$ Tween- 20 at $50^{\circ} \mathrm{C}$ for at least 2 hours. Hybridization was performed overnight at $50^{\circ} \mathrm{C}$. Larvae were then washed 6 times in $50 \%$ formamide, $5 \times \mathrm{SSC}, 0.1 \%$ Tween 20 for 20 min, rinsed in PBT and transferred in blocking solution (goat serum: PBT, 1:4) for 2 hours. Samples were incubated overnight at $4^{\circ} \mathrm{C}$ in blocking solution with anti-DIG antibody $(1: 2000)$. After 
1 washes in PBT, staining reaction was carried out in APT buffer $(100 \mathrm{mM} \mathrm{NaCl}, 100 \mathrm{mM}$ Tris $\mathrm{HCl}$, $2 \mathrm{pH} 9.5,50 \mathrm{mM} \mathrm{MgCl} 2,0.1 \%$ Tween-20) $+2.3 \mu \mathrm{l} / \mathrm{ml}$ NBT and $3.5 \mu \mathrm{l} / \mathrm{ml} \mathrm{BCIP}$. When satisfactory 3 signal was obtained, embryos were fixed for $1 \mathrm{hr}$ in $4 \%$ paraformaldehyde, mounted in glycerol and 4 photographed under an optical microscope equipped with Leica DFC-320 Camera.

5 DIG-labelled riboprobe were synthetized as previously described (Mercurio et al., 2019) and the 6 following neural markers genes were used: $\mathrm{Ci}$-Pans, to investigate larvae neural architecture (Alfano 7 et al., 2007); Ci-Syn, encoding for specific synaptic molecules associated with synapsis (Candiani et 8 al., 2010) and $\mathrm{Ci}-\mathrm{TH}$ to explore differentiation of dopaminergic neurons (Moret et al., 2005).

\section{$9 \quad$ 2.6. Statistical analysis}

10 ANOVA analysis of variance, followed by HSD Tukey's post hoc test, was performed to assess the 11 effect of TCPP larval development. Prior to analyses, we verified the homogeneity and normality of 12 the variances. Probit analysis was performed following the simple least squares regression method to 13 calculate median lethal concentration $\left(\mathrm{LC}_{50}\right)$ and median effective concentration $\left(\mathrm{EC}_{50}\right)$. All the 14 analyses were performed in the R 3.6.3 environment (R. Core Team, 2019).

\section{Results}

\subsection{Effects on embryonic development}

18 Adverse effect was evaluated at the hatching larva stage (Hotta et al., 2007). Larvae general morphology was examined under a dissecting microscope (Fig. 1 A). Control larvae appeared normally developed, typically swimming upward with their straight and motile tail. Low concentrations of TCPP did not affect larval development (Fig. 1). A significant increase of malformed samples was observed from $50 \mu \mathrm{g} / \mathrm{ml}$ (Fig. $1 \mathrm{~B}$; ANOVA: $\mathrm{F}_{9,29}=13.49$, p $<0.0001$;

23 Tukey's post hoc test: controls $v s 50 \mu \mathrm{g} / \mathrm{ml}, \mathrm{p}<0.01$; controls $v s 65 \mu \mathrm{g} / \mathrm{ml}, \mathrm{p}<0.01$ ). Malformations were mainly at the tail, which was bent in one or more sites, preventing larvae swimming activity. Dead embryos did not hatch and/or displayed a very compromised morphology (Fig. 1 A) and their percentage was found significantly higher than controls at 75 and $100 \mu \mathrm{g} / \mathrm{ml}$ TCPP (Fig. $1 \mathrm{~B}$; ANOVA: $\mathrm{F}_{9,29}=18.38, \mathrm{p}<0.0001$; Tukey's post hoc test: controls $v s 75 \mu \mathrm{g} / \mathrm{ml}, \mathrm{p}<0.0001$; controls $28 v s 100 \mu \mathrm{g} / \mathrm{ml}, \mathrm{p}<0.0001)$.

\section{$29 \quad$ 3.2. Probit analyses}

30 During ascidians embryogenesis, TCPP exposure increased the occurrence of larval malformations 31 and mortality. The concentration at which 50\% of exposed samples were malformed (median 32 effective concentration; $\left.\mathrm{EC}_{50}\right)$ was $51.16 \mu \mathrm{g} / \mathrm{ml}(95 \% \mathrm{CI}$ for the coefficient estimates [0.03, 0.04]) 
1 (Fig. 2 A). The median lethal concentration $\left(\mathrm{LC}_{50}\right)$ was $66.18 \mu \mathrm{g} / \mathrm{ml}(95 \%$ CI for the coefficient 2 estimates $[0.02,0.04])$ (Fig. $2 \mathrm{~B})$. TCPP teratogenic index $\left(\mathrm{TI}=\mathrm{LC}_{50} / \mathrm{EC}_{50}\right)$ resulted 1.29.

3 3.3. Larval morphology

4 Larvae morphology was carefully evaluated under an optical microscope (Fig. 3 A-F). Larvae 5 developed in FSW or $0.1 \%$ DMSO as well as those exposed to TCPP lower concentrations showed a normal phenotype (Fig. 3 A). Larval trunk appeared elongated with a well-developed sensory vesicle containing the two pigmented sensory organs: the gravity sensing otolith and the photoreceptive organ, the ocellus (Fig. 3 B). Tail was long and straight, characterized by bands of well-differentiated muscle cells flanking the rod-like notochord (Fig. 3 C). Light microscopy analysis of these samples confirmed their normal anatomy (Fig. $3 \mathrm{G}$ and $\mathrm{H}$ ).

Malformed larvae generally showed a normally developed trunk but a bent tail in which one or more peculiar big cells localized in correspondence of the bend point (Fig. 3 D and E). Microscopy examination allowed a better characterization of these cells (Fig. 3 I-K). They appeared ovoid in shape, as undifferentiated embryonic cells, with a big central nucleus and homogenous cytoplasm; they were 20-30 $\mu \mathrm{m}$ long and about $10 \mu \mathrm{m}$ large. These cells were much bigger than the surrounding muscles cells and were located just under the epidermis. Finally, dead larvae displayed a disrupted morphology, particularly at the level of the tail (Fig. 3 F).

\subsection{Effects on neural development}

To explore TCPP effects on neurogenesis, we first examined neural fibers pattern of control and treated larvae performing fluorescent immunostaining with anti- $\beta$-tubulin antibody (Fig. 4). Control larvae reared in FSW or $0.1 \%$ DMSO displayed a normal neural fibers organization. In the trunk, nerves can be observed running from the 3 papillary neurons (in the frontmost area of the larva) to the sensory vesicle, which appeared partially enclosed by neural fibers. In the tail, antibody-positive fibers localized in the dorsal neural tube; cilia of the tail epidermal sensory neurons were also marked (Fig. 4 A). Nerves development of larvae exposed to $25 \mu \mathrm{g} / \mathrm{ml} \mathrm{TCPP} \mathrm{(Fig.} 4$ B) appeared comparable to controls. On the contrary, samples treated with $50 \mu \mathrm{g} / \mathrm{ml}$ TCPP showed a severe disruption of fibers arrangement: even if some $\beta$-tubulin-positive fibers were present, they appeared strongly reduced in number and extension (Fig. 4 C).

To better characterized TCPP impact on neural development, we performed in situ hybridizations with neural markers. $\mathrm{Ci}$-Pans was used to investigate the general architecture of larval nervous system (Alfano et al., 2007). In control samples the gene was expressed in the central nervous system, comprising the sensory vesicle and the following motor ganglion in the trunk and the dorsal neural tube in the tail (Fig. $5 \mathrm{~A}$ and C). Ci-Pans expression pattern was normal in larvae exposed to either 
125 or $50 \mu \mathrm{g} / \mathrm{ml}$ TCPP and the signal was comparable to controls one (Fig. 5 B, D and E). Ci-Syn 2 encodes for synapsins, specific synaptic molecules associated with synapsis (Candiani et al., 2010).

3 In controls, $C i-S y n$ transcripts were present in the completely differentiated nervous system, 4 recapitulating Ci-Pans expression pattern (Fig. $5 \mathrm{~F}$ and $\mathrm{H}$ ). In larvae treated with to 25 and $50 \mu \mathrm{g} / \mathrm{ml}$ 5 TCPP gene signal appeared only slightly irregular (Fig. 5 G, I and J). Finally, since previous work suggested TCPP interference with dopaminergic system (Xu et al., 2016), we studied the differentiation of dopamine neurons using $\mathrm{Ci}$-TH (Moret et al., 2005) as marker. Comparing the

8 expression of this gene among control and treated larvae no difference was observed: in all samples: 9 dopaminergic cells were always found in the ventral middle region of the sensory vesicle (Fig. 5 K$10 \mathrm{M})$.

\section{Discussion}

Tris(1-chloro-2-propyl)phosphate (TCPP) is the organophosphorus flame retardant (OPFR) with the highest production volume in Europe (Ekpe et al., 2020). It is considered ubiquitous in the environment, being detected in water, soil and even air (Wang et al., 2020). Nevertheless, TCPP toxicity was mostly assessed in vitro or in vertebrate models, leaving a big gap of knowledge about its adverse effects on invertebrates. Among them, marine and freshwater invertebrates are particularly threatened by environmental pollutants as the most sensitive phases of their lifecycles, i.e. fertilization and embryonic development, occur in the water column, directly in contact with any anthropogenic contaminants. Thus, in the present study, we investigated TCPP adverse effects on the embryogenesis of the marine invertebrates, $C$. intestinalis, providing new important toxicological data about this flame retardant.

Indeed, TCPP adversely affected embryos development and survival: the calculated $\mathrm{EC}_{50}$ resulted $51.16 \mu \mathrm{g} / \mathrm{ml}$ while the $\mathrm{LC}_{50}$ value was $66.18 \mu \mathrm{g} / \mathrm{ml}$, close to that reported for the freshwater invertebrate, Daphnia magna (81 mg/l) (Cristale et al., 2013). During ascidian development, TCPP exposure caused specific malformations in larvae tail. Malformed samples were indeed characterized by bent tails in which one or two big cells were evident just before the bend point. Microscopic analysis confirmed the presence of these peculiar cells among muscle fibers, just under the epidermis. Based on their localization and appearance, these ovoid cells could be embryonic muscle cells that did not proceed further in the differentiation process. To the best of our knowledge, TCPP adverse effects on myogenesis has never been reported before but adverse effects on muscular system have already been described for other OPFRs in zebrafish. Alterations in assembly of muscle fibers and muscular genes expression have been documented in zebrafish larvae and one-month old females after exposure to tris(1,3-dichloro-2-propyl)phosphate (TDCIPP) or triphenyl phosphate (Noyes et 
1 al., 2015; Rhyu et al., 2019; Shi et al., 2019; Zhu et al., 2018). Particularly, TDCIPP caused specific morphological defects of tail fin, which included bent spine, defective caudal fin and damaged caudal tip. Although the TDCIPP precise mechanism of action was not demonstrated, morphological and molecular investigations revealed that malformations were associated with mis-expression of transcription factors involved in muscles development (Rhyu et al., 2019). Similar modifications in gene expression could be responsible for ascidian tail malformations. Ascidians development is characterized by invariant cell lineage, thus the fate of each blastomere can be precisely traced. During C. intestinalis embryogenesis, muscle cells derive from 3 cell types, the A- B- and b-lines of the 8-cells stage embryo. The bulk of tail muscle fibers derives from B-lineage cells (primary muscles), whereas A- and b- cells develop in the secondary muscles (Hudson \& Yasuo, 2008; RazyKrajka \& Stolfi, 2019). Based on our analyses, it was not possible to identify which type of muscles (primary or secondary) was affected by TCPP. b-line derived muscles could be excluded as they are always located at the tip of the tail. A- and B-line muscles develop through completely different gene regulatory cascades, but the Myogenic regulatory factor (Mrf) is involved in the specification networks of both types. Ciona Mrf was formerly known as $C i-M D F$ or $M y o D$ and is the ortholog of all vertebrate MRF genes (Razy-Krajka and Stolfi, 2019). In C. intestinalis, Mrf downregulation via morpholino induced a phenotype strikingly similar to that observed after TCPP exposure: larvae generally displayed a normal morphology with the exception of the kinked tail (Meedel et al., 2007). Since genes belonging to MRF family, such as Myf5 and MyoD, were mis-expressed after TDCIPP exposure in zebrafish (Rhyu et al., 2019; Zhu et al., 2018), it could be proposed that also TCPP affected ascidian myogenesis through $M r f$ gene network.

22 As OPFRs neurotoxicity has been extensively documented in both vertebrates and invertebrates (Du 23 et al., 2019; Ji et al., 2020; Noyes et al., 2015; C. Wang et al., 2020; X. Wang et al., 2020; Xu et al., 24 2016), we focused on TCPP effects on ascidian neural development. In situ hybridizations revealed that the general architecture of larval central nervous system was not affected by TCPP exposure as the expression of $\mathrm{Ci}$-Pans was comparable between control and treated embryos. Moreover, dopaminergic neurons were normally differentiated in all the samples. However, larvae developed in presence of $50 \mu \mathrm{g} / \mathrm{ml}$ TCPP displayed alterations in neural fibers development and arrangement. Impairment of axonal growth and branching has been already demonstrated for many OPFRs, including TCPP. For example, in the rockfish Sebastes schlegeli, proteome responses to TCPP exposure included alterations in cytoskeletal protein levels as well as disruption of neurotransmission-associated molecules such as synapsin I (Ji et al., 2020). Hence, in ascidians, TCPP neurotoxicity seemed to be correlated to synapsis formation and neural fibers outgrowth whereas no effect on neurons differentiation and survival were observed. 
1 In conclusion, we investigated TCPP adverse effects on the most sensitive phase of ascidians lifecycle 2 providing important novel information about this extremely common OPFR in marine environment. $3 \mathrm{EC}_{50}$ value resulted far from TCPP environmental concentrations but malformations observed in 4 muscles and nervous system development were reported for many other OPFRs, suggesting that 5 OPFRs could share common mechanisms of action. Since marine animals are simultaneously exposed 6 to a cocktail of different pollutants, it is very important to study their molecular interactions to 7 determine if they can act jointly, leading to additive effects that can affect individual survival and 8 population sustainability.

\section{5. Acknowledgements}

11 Part of this work was carried out at NOLIMITS, an advanced imaging facility established by the 12 Università degli Studi di Milano. Particularly, the authors are grateful to Miriam Ascagni for technical 13 support at confocal microscope.

\section{Conflict of interest}

16 The authors declare that they have no known competing financial interests or personal relationships 17 that could influence the work reported in this paper.

\section{Funding}

This work was supported by the ASSEMBLE PLUS Project (European Union's Horizon 2020 research and innovation program, Grant Agreement No. 730984).

\section{Figure captions}

Fig. 1. Effects of TCPP on embryonic development of $C$. intestinalis. A) General morphology of C. intestinalis larvae exposed to different concentrations of TCPP. Scale bar: $200 \mu \mathrm{m}$. B) Percentages of normal, malformed and dead larvae of $C$. intestinalis exposed to TCPP. Legend of symbols: $*$ differences from control; the repetition of each symbol indicates the level of significance: $* \mathrm{p}<0.05$, $* * \mathrm{p}<0.001, * * * \mathrm{p}<0.0001$.

Fig. 2. TCPP dose response curves for malformations (A) and mortality (B) in C. intestinalis. $\mathrm{EC}_{50}(\mathrm{~A})$ and $\mathrm{LC}_{50}(\mathrm{~B})$ values were calculated by probit models.

\section{Fig. 3. Morphological analysis of $C$. intestinalis larvae: (A-F) whole mount and (G-K) light} microscopy evaluation. A) Control larva developed in in $0.1 \%$ DMSO in ASWH showing the typical elongated trunk and the straight long tail. B) Magnification of the trunk of a control larva in which can be appreciated the sensory vesicle (SV) containing the otolith (Ot) and the ocellus (Oc). C) 
1 Magnification of the tail of a control sample: under the epidermis (e) muscle cells (m) flank the rod2 like notochord (n). D) Malformed larva developed in $50 \mu \mathrm{g} / \mathrm{ml} \mathrm{TCPP}$; in the bent tail a big cell 3 (arrowhead) can be observed. E) Magnification of a bent tail displaying the peculiar ovoid cell 4 (arrowhead) just at the bend point. F) Dead larva with a highly compromised morphology. G) 5 Longitudinal section of a control larva: in the trunk, the cavity of the sensory vesicle (SV) with the ocellus (Oc) is observable. H) Magnification of the tail of a control in which the epidermis (e), the underneath muscles and the central notochord can be appreciated. Outside, tunic cells $(*)$ are also present. I-J) Longitudinal sections of two malformed larvae showing big ovoid cells (arrowheads) among the tail muscles. K) Magnification of a malformed tail: the big undifferentiated cell is localized among muscle cells (m); the external tunic cells $(*)$, the epidermis (e) and the notochord (n) are also visible.

Fig. 4. Immunostaining of the nervous system fibers with anti $\beta$-tubulin antibody in Ciona intestinalis: bright field and fluorescent images. Larva developed in ASWH with $0.1 \%$ DMSO (A), in $25 \mu \mathrm{g} / \mathrm{ml} \mathrm{TCPP} \mathrm{(B)} \mathrm{and} 50 \mu \mathrm{g} / \mathrm{ml}$ TCPP (C). Legend of symbols: SV: sensory vesicle; NT: neural tube; <: cilium of a tail epidermal sensory neuron; *: papillary neuron.

Fig. 5. Whole mount in situ hybridizations of $C$. intestinalis larvae with neural markers. (A-E) Ci-Pans expression in controls (A and C) and larvae developed in $25 \mu \mathrm{g} / \mathrm{ml}$ TCPP (B and D) and 50 $\mu \mathrm{g} / \mathrm{ml} \mathrm{TCPP} \mathrm{(E):} \mathrm{the} \mathrm{central} \mathrm{nervous} \mathrm{system,} \mathrm{comprising} \mathrm{the} \mathrm{sensory} \mathrm{vesicle} \mathrm{(SV),} \mathrm{the} \mathrm{motor} \mathrm{ganglion}$ (MG) and the neural tube (NT), is strongly marked. (F-J) Ci-Syn expression in controls (F and H) and larvae developed in $25 \mu \mathrm{g} / \mathrm{ml}$ TCPP (G and I) and $50 \mu \mathrm{g} / \mathrm{ml}$ TCPP (J). (K-M) Ci-TH expression in control (K) and larvae exposed to TCPP (L and M). Scale bar: $100 \mu \mathrm{m}$.

\section{References}

Alfano, C., Teresa Russo, M., \& Spagnuolo, A. (2007). Developmental expression and transcriptional regulation of $\mathrm{Ci}$-Pans, a novel neural marker gene of the ascidian, Ciona intestinalis. Gene, 406(1-2), 36-41. https://doi.org/10.1016/j.gene.2007.05.026

Bekele, T. G., Zhao, H., Wang, Q., \& Chen, J. (2019). Bioaccumulation and Trophic Transfer of Emerging Organophosphate Flame Retardants in the Marine Food Webs of Laizhou Bay, North China. Environmental Science \& Technology, 53(22), 13417-13426. https://doi.org/10.1021/acs.est.9b03687

Candiani, S., Moronti, L., Pennati, R., De Bernardi, F., Benfenati, F., \& Pestarino, M. (2010). The synapsin gene family in basal chordates: evolutionary perspectives in metazoans. $B M C$ Evolutionary Biology, 10, 32. https://doi.org/10.1186/1471-2148-10-32

Cristale, J., García Vázquez, A., Barata, C., \& Lacorte, S. (2013). Priority and emerging flame 

2

retardants in rivers: Occurrence in water and sediment, Daphnia magna toxicity and risk assessment. Environment International, 59, 232-243. https://doi.org/https://doi.org/10.1016/j.envint.2013.06.011

Cuvillier-Hot, V., \& Lenoir, A. (2020). Invertebrates facing environmental contamination by endocrine disruptors: Novel evidences and recent insights. Molecular and Cellular Endocrinology, 504, 110712. https://doi.org/https://doi.org/10.1016/j.mce.2020.110712

Delsuc, F., Brinkmann, H., Chourrout, D., \& Philippe, H. (2006). Tunicates and not cephalochordates are the closest living relatives of vertebrates. Nature, 439(7079), 965-968. https://doi.org/10.1038/nature04336

Dishaw, L. V, Hunter, D. L., Padnos, B., Padilla, S., \& Stapleton, H. M. (2014). Developmental Exposure to Organophosphate Flame Retardants Elicits Overt Toxicity and Alters Behavior in Early Life Stage Zebrafish (Danio rerio). Toxicological Sciences, 142(2), 445-454. https://doi.org/10.1093/toxsci/kfu194

Du, J., Li, H., Xu, S., Zhou, Q., Jin, M., \& Tang, J. (2019). A review of organophosphorus flame retardants (OPFRs): occurrence, bioaccumulation, toxicity, and organism exposure. Environmental Science and Pollution Research, 26(22), 22126-22136. https://doi.org/10.1007/s11356-019-05669-y

Ekpe, O. D., Choo, G., Barceló, D., \& Oh, J.-E. (2020). Chapter One - Introduction of emerging halogenated flame retardants in the environment. In J.-E. B. T.-C. A. C. Oh (Ed.), Emerging Halogenated Flame Retardants in the Environment (Vol. 88, pp. 1-39). Elsevier. https://doi.org/https://doi.org/10.1016/bs.coac.2019.11.002

Eliso, M. C., Manfra, L., Savorelli, F., Tornambè, A., \& Spagnuolo, A. (2020). New approaches on the use of tunicates (Ciona robusta) for toxicity assessments. Environmental Science and Pollution Research. https://doi.org/10.1007/s11356-020-09781-2

Farhat, A., Crump, D., Chiu, S., Williams, K. L., Letcher, R. J., Gauthier, L. T., \& Kennedy, S. W. (2013). In Ovo effects of two organophosphate flame retardants--TCPP and TDCPP--on pipping success, development, mRNA expression, and thyroid hormone levels in chicken embryos. Toxicological Sciences : An Official Journal of the Society of Toxicology, 134(1), 92-102. https://doi.org/10.1093/toxsci/kft100

Hotta, K., Mitsuhara, K., Takahashi, H., Inaba, K., Oka, K., Gojobori, T., \& Ikeo, K. (2007). A web-based interactive developmental table for the ascidian Ciona intestinalis, including 3D real-image embryo reconstructions: I. From fertilized egg to hatching larva. Developmental Dynamics, 236(7), 1790-1805. https://doi.org/10.1002/dvdy.21188

Hudson, C., \& Yasuo, H. (2008). Similarity and diversity in mechanisms of muscle fate induction 
between ascidian species. Biology of the Cell, 100(5), 265-277.

https://doi.org/10.1042/BC20070144

Ji, C., Lu, Z., Xu, L., Li, F., Cong, M., Shan, X., \& Wu, H. (2020). Global responses to tris(1chloro-2-propyl)phosphate (TCPP) in rockfish Sebastes schlegeli using integrated proteomic and metabolomic approach. Science of The Total Environment, 724, 138307. https://doi.org/https://doi.org/10.1016/j.scitotenv.2020.138307

Li, J., Xie, Z., Mi, W., Lai, S., Tian, C., Emeis, K.-C., \& Ebinghaus, R. (2017). Organophosphate \& Technology, 51(12), 6887-6896. https://doi.org/10.1021/acs.est.7b01289

Meedel, T. H., Chang, P., \& Yasuo, H. (2007). Muscle development in Ciona intestinalis requires the b-HLH myogenic regulatory factor gene Ci-MRF. Developmental Biology, 302(1), 333344. https://doi.org/https://doi.org/10.1016/j.ydbio.2006.09.043

Mercurio, S., Cauteruccio, S., Manenti, R., Candiani, S., Scarì, G., Licandro, E., \& Pennati, R. (2019). Mir-7 knockdown by peptide nucleic acids in the ascidian Ciona intestinalis. International Journal of Molecular Sciences, 20(20). https://doi.org/10.3390/ijms20205127

Messinetti, S., Mercurio, S., \& Pennati, R. (2018). Effects of bisphenol A on the development of pigmented organs in the ascidian Phallusia mammillata. Invertebrate Biology, 137(4). https://doi.org/10.1111/ivb.12231

Messinetti, S., Mercurio, S., \& Pennati, R. (2019). Bisphenol A affects neural development of the ascidian Ciona robusta. Journal of Experimental Zoology Part A: Ecological and Integrative Physiology, 331(1). https://doi.org/10.1002/jez.2230

Messinetti, S., Mercurio, S., Scarì, G., Pennati, A., \& Pennati, R. (2019). Ingested microscopic plastics translocate from the gut cavity of juveniles of the ascidian Ciona intestinalis. European Zoological Journal, 86(1). https://doi.org/10.1080/24750263.2019.1616837

Moret, F., Christiaen, L., Deyts, C., Blin, M., Joly, J.-S., \& Vernier, P. (2005). The dopaminesynthesizing cells in the swimming larva of the tunicate Ciona intestinalis are located only in the hypothalamus-related domain of the sensory vesicle. The European Journal of Neuroscience, 21(11), 3043-3055. https://doi.org/10.1111/j.1460-9568.2005.04147.x

Noyes, P. D., Haggard, D. E., Gonnerman, G. D., \& Tanguay, R. L. (2015). Advanced Morphological - Behavioral Test Platform Reveals Neurodevelopmental Defects in Embryonic Zebrafish Exposed to Comprehensive Suite of Halogenated and Organophosphate Flame Retardants. Toxicological Sciences, 145(1), 177-195. https://doi.org/10.1093/toxsci/kfv044

R Core Team. (2019). A Language and Environment for Statistical Computing, Version 3.5. 3. 
Vienna: R Foundation for Statistical Computing.

Razy-Krajka, F., \& Stolfi, A. (2019). Regulation and evolution of muscle development in tunicates. EvoDevo, 10(1), 13. https://doi.org/10.1186/s13227-019-0125-6

Rhyu, D., Lee, H., Tanguay, R. L., \& Kim, K.-T. (2019). Tris(1,3-dichloro-2-propyl)phosphate (TDCIPP) disrupts zebrafish tail fin development. Ecotoxicology and Environmental Safety, 182, 109449. https://doi.org/https://doi.org/10.1016/j.ecoenv.2019.109449

Sepúlveda, R., Rozbaczylo, N., Ibáñez, C., Flores, M., \& Cancino, J. (2014). Ascidian-associated polychaetes: ecological implications of aggregation size and tube-building chaetopterids on assemblage structure in the Southeastern Pacific Ocean. Marine Biodiversity. https://doi.org/10.1007/s12526-014-0283-7

Shi, Q., Tsui, M. M. P., Hu, C., Lam, J. C. W., Zhou, B., \& Chen, L. (2019). Acute exposure to triphenyl phosphate (TPhP) disturbs ocular development and muscular organization in zebrafish larvae. Ecotoxicology and Environmental Safety, 179, 119-126. https://doi.org/https://doi.org/10.1016/j.ecoenv.2019.04.056

Sundkvist, A. M., Olofsson, U., \& Haglund, P. (2010). Organophosphorus flame retardants and plasticizers in marine and fresh water biota and in human milk. Journal of Environmental Monitoring, 12(4), 943-951. https://doi.org/10.1039/B921910B

Truong, J. W., Diamond, M. L., Helm, P. A., \& Jantunen, L. M. (2017). Isomers of tris(chloropropyl) phosphate (TCPP) in technical mixtures and environmental samples. Analytical and Bioanalytical Chemistry, 409(30), 6989-6997. https://doi.org/10.1007/s00216017-0572-7

Wang, C., Chen, Z., Lu, Y., Wang, L., Zhang, Y., Zhu, X., \& Song, J. (2020). Neurotoxicity and related mechanisms of flame retardant TCEP exposure in mice. Toxicology Mechanisms and Methods, 1-7. https://doi.org/10.1080/15376516.2020.1765060

Wang, X., Zhu, Q., Yan, X., Wang, Y., Liao, C., \& Jiang, G. (2020). A review of organophosphate flame retardants and plasticizers in the environment: Analysis, occurrence and risk assessment. Science of The Total Environment, 731, 139071. https://doi.org/https://doi.org/10.1016/j.scitotenv.2020.139071

Wu, H., Zhong, M., Lu, Z., Shan, X., Li, F., Ji, C., \& Cong, M. (2018). Biological effects of tris (1chloro-2-propyl) phosphate (TCPP) on immunity in mussel Mytilus galloprovincialis. Environmental Toxicology and Pharmacology, 61, 102-106. https://doi.org/https://doi.org/10.1016/j.etap.2018.05.022

Xu, T., Li, P., Wu, S., Lei, L., \& He, D. (2016). Tris(2-chloroethyl) phosphate (TCEP) and tris(2chloropropyl) phosphate (TCPP) induce locomotor deficits and dopaminergic degeneration in 
1 Caenorhabditis elegans. Toxicology Research, 6(1), 63-72.

2 https://doi.org/10.1039/c6tx00306k

3 Zhong, M., Tang, J., Guo, X., Guo, C., Li, F., \& Wu, H. (2020). Occurrence and spatial distribution

4 of organophosphorus flame retardants and plasticizers in the Bohai, Yellow and East China $5 \quad$ seas. Science of The Total Environment, 741, 140434.

6 https://doi.org/https://doi.org/10.1016/j.scitotenv.2020.140434

7 Zhu, Y., Lin, D., Yang, D., Jia, Y., \& Liu, C. (2018). Environmentally relevant concentrations of 8 the flame retardant tris(1,3-dichloro-2-propyl) phosphate change morphology of female 9 zebrafish. Chemosphere, 212, 358-364.

$10 \quad$ https://doi.org/https://doi.org/10.1016/j.chemosphere.2018.08.083 

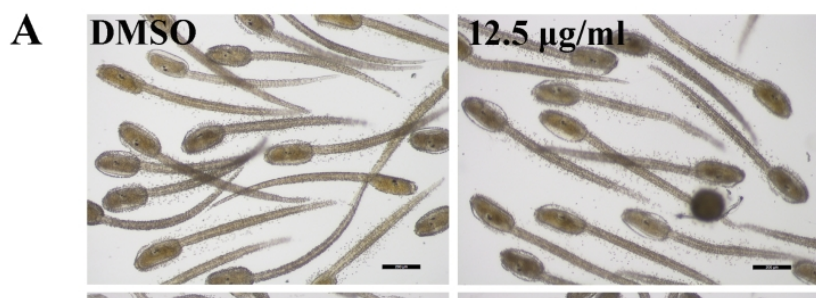

\section{$25 \mu \mathrm{g} / \mathrm{ml}$}
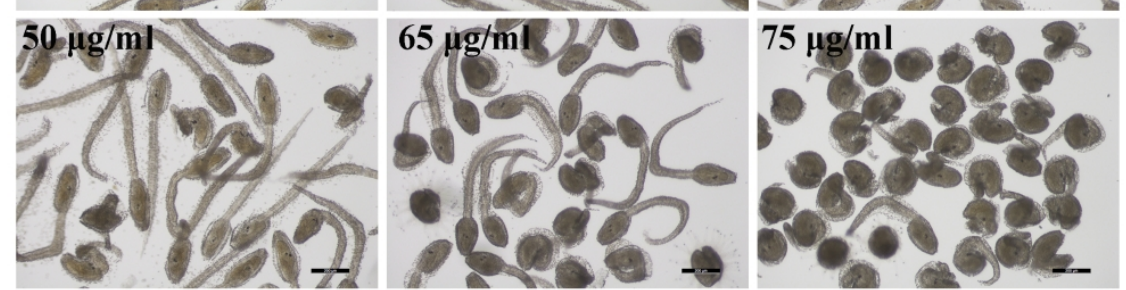

B

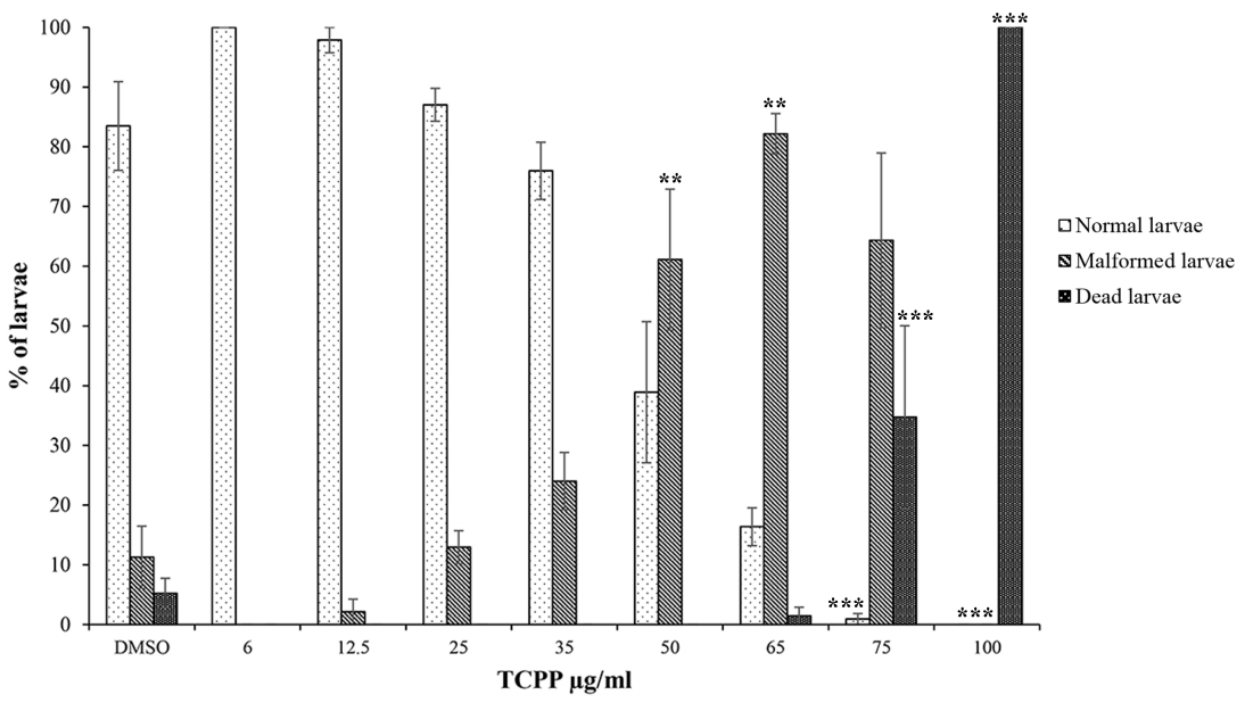

Fig. 1. Effects of TCPP on embryonic development of C. intestinalis. A) General morphology of C. intestinalis larvae exposed to different concentrations of TCPP. Scale bar: $200 \mu \mathrm{m}$. B) Percentages of normal, malformed and dead larvae of $C$. intestinalis exposed to TCPP. Legend of symbols: *differences from control; the repetition of each symbol indicates the level of significance: $* p<0.05, * * p<0.001, * * *$ $\mathrm{p}<0.0001$. 
A
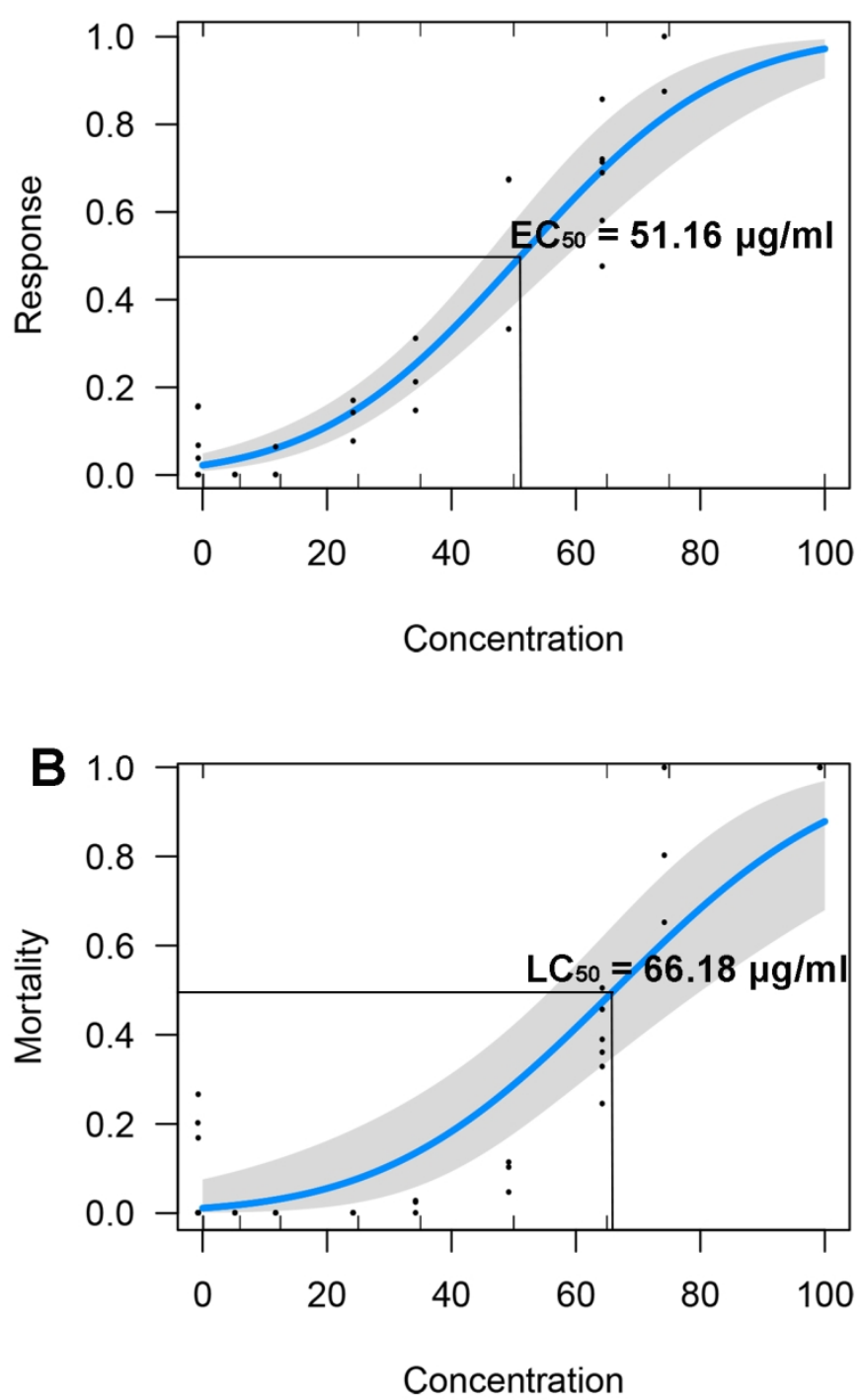

Fig. 2. TCPP dose response curves for malformations (A) and mortality (B) in C. intestinalis. EC50 (A) and LC50 (B) values were calculated by probit models. 

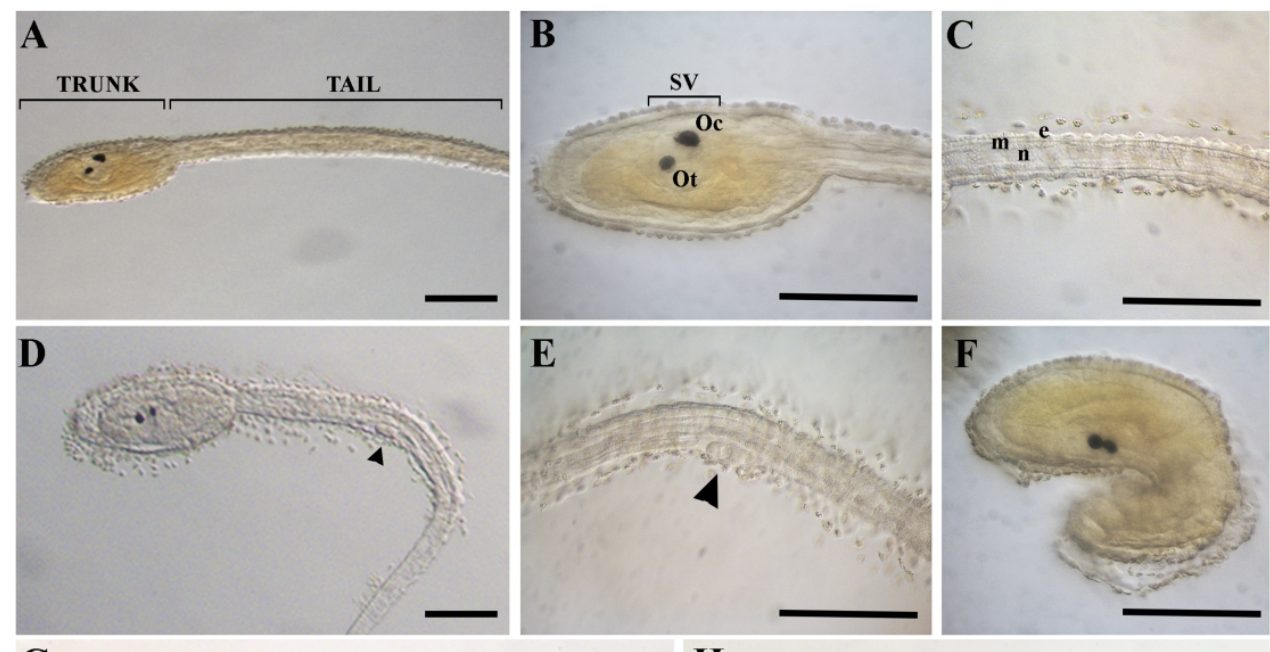

G
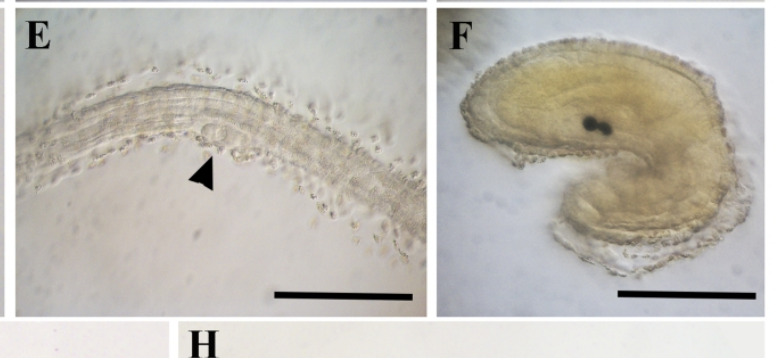

H
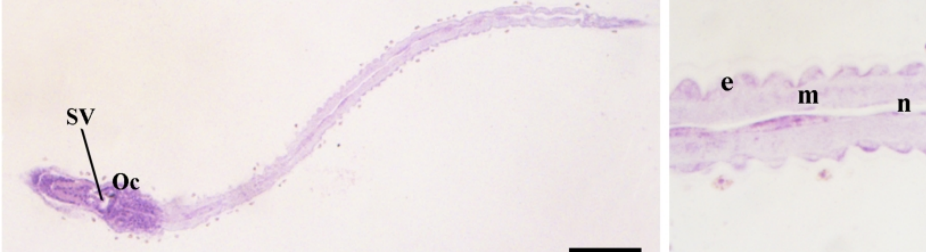

I

J

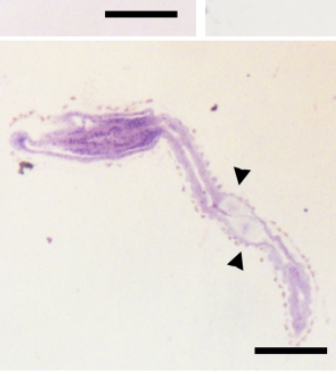

K
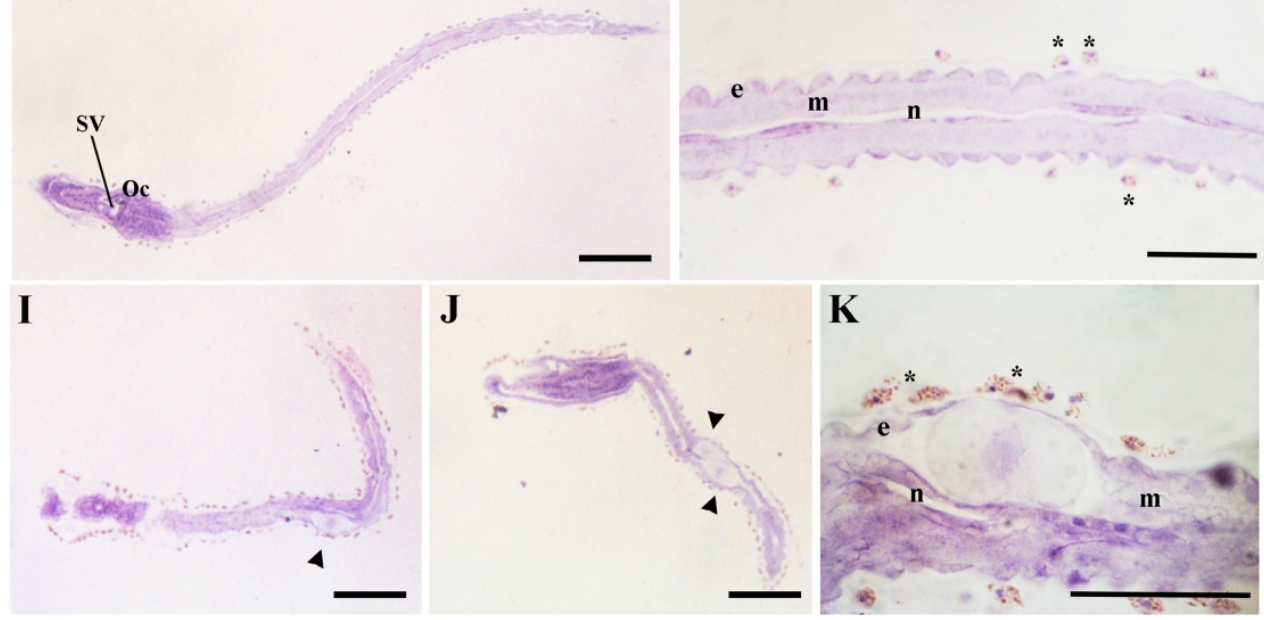

Fig. 3. Morphological analysis of $C$. intestinalis larvae: (A-F) whole mount and (G-K) light microscopy evaluation. A) Control larva developed in in 0.1\% DMSO in ASWH showing the typical elongated trunk and the straight long tail. B) Magnification of the trunk of a control larva in which can be appreciated the sensory vesicle (SV) containing the otolith (Ot) and the ocellus (Oc). C) Magnification of the tail of a control sample: under the epidermis (e) muscle cells $(\mathrm{m})$ flank the rod-like notochord ( $\mathrm{n})$. D) Malformed larva developed in

$50 \mu \mathrm{g} / \mathrm{ml} \mathrm{TCPP}$; in the bent tail a big cell (arrowhead) can be observed. E) Magnification of a bent tail displaying the peculiar ovoid cell (arrowhead) just at the bend point. F) Dead larva with a highly compromised morphology. G) Longitudinal section of a control larva: in the trunk, the cavity of the sensory vesicle (SV) with the ocellus (Oc) is observable. $\mathrm{H}$ ) Magnification of the tail of a control in which the epidermis (e), the underneath muscles and the central notochord can be appreciated. Outside, tunic cells (*) are also present. I-J) Longitudinal sections of two malformed larvae showing big ovoid cells (arrowheads) among the tail muscles. K) Magnification of a malformed tail: the big undifferentiated cell is localized among muscle cells $(m)$; the external tunic cells $(*)$, the epidermis (e) and the notochord $(n)$ are also visible. 
Fig. 4. Immunostaining of the nervous system fibers with anti $\beta$-tubulin antibody in Ciona intestinalis: bright field and fluorescent images. Larva developed in ASWH with $0.1 \%$ DMSO (A), in $25 \mu \mathrm{g} / \mathrm{ml}$ TCPP (B) and 50 $\mu \mathrm{g} / \mathrm{ml}$ TCPP (C). Legend of symbols: SV: sensory vesicle; NT: neural tube; <: cilium of a tail epidermal sensory neuron; *: papillary neuron.
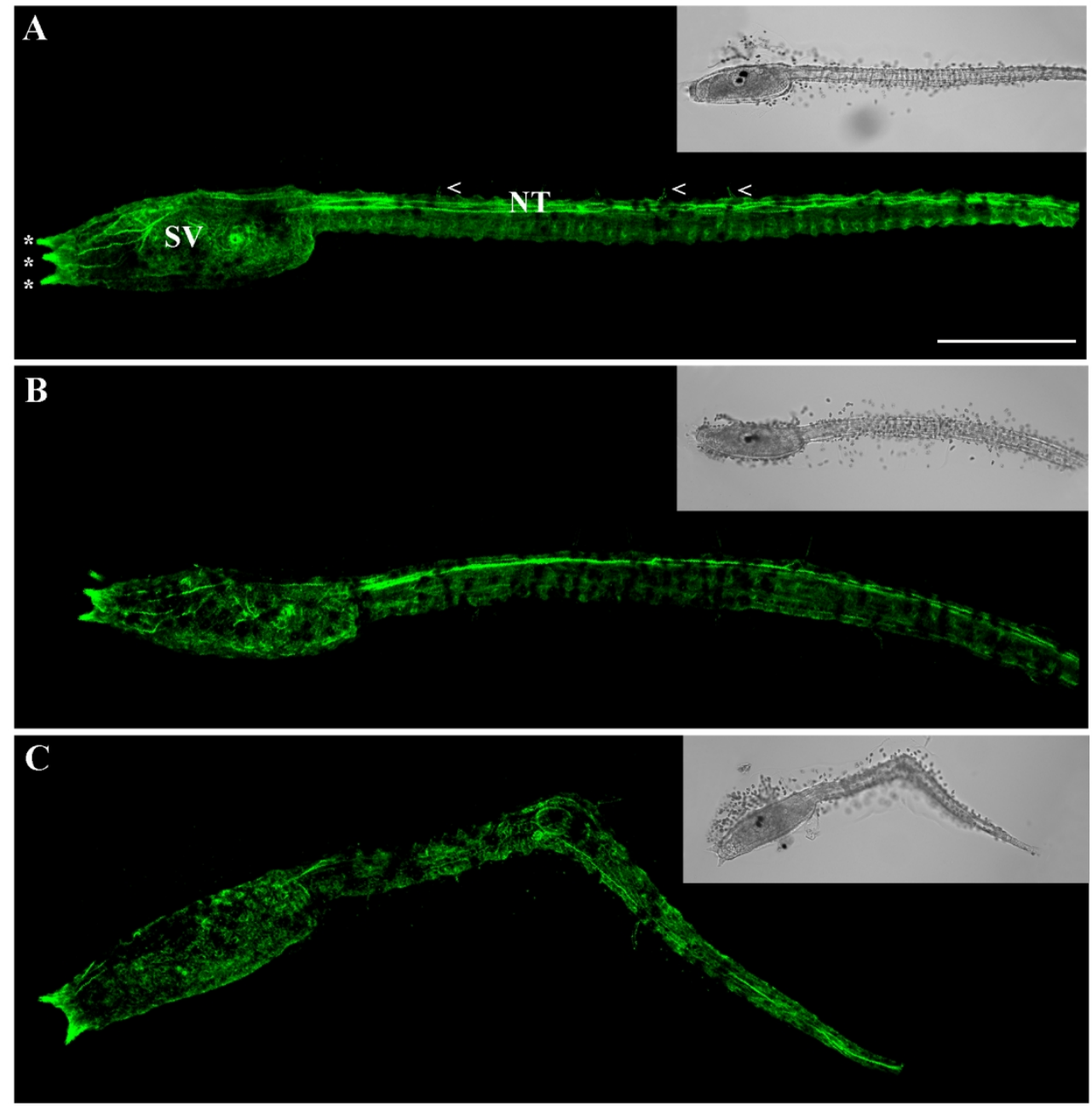

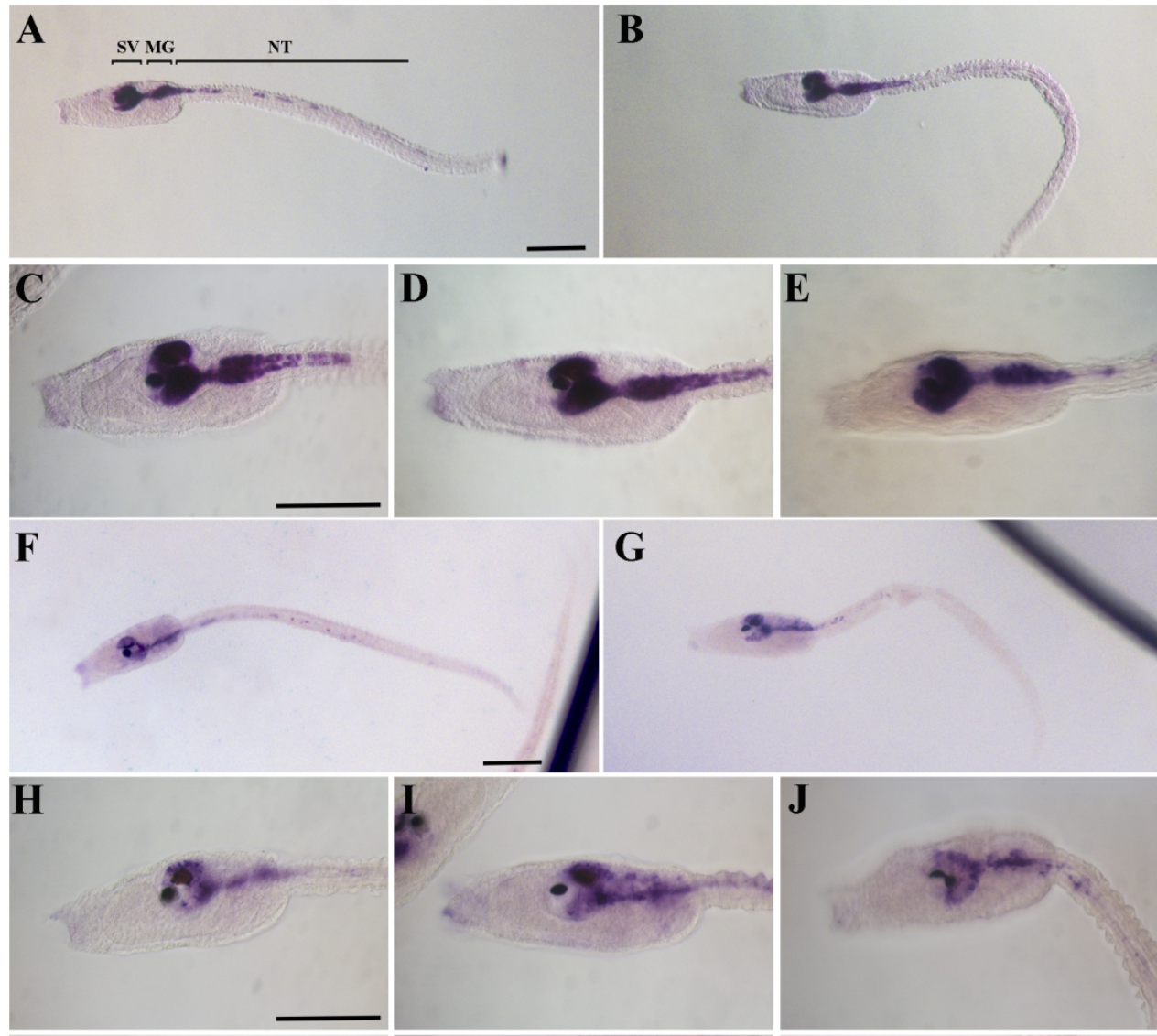

G
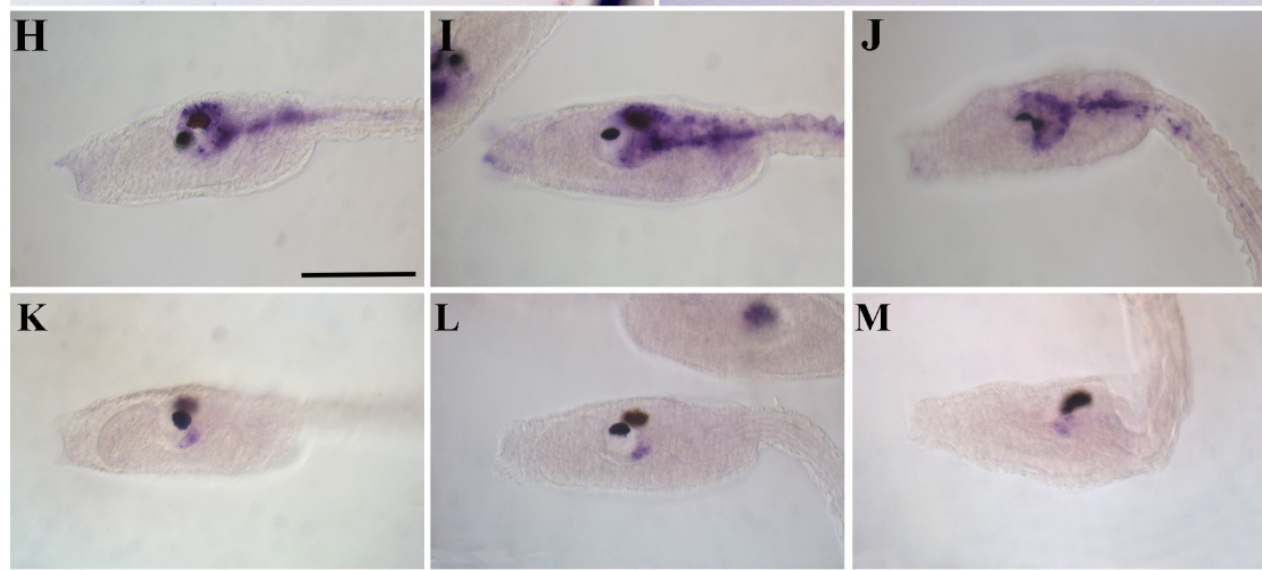

M

Fig. 5. Whole mount in situ hybridizations of $C$. intestinalis larvae with neural markers. (A-E) Ci-Pans expression in controls ( $A$ and $C$ ) and larvae developed in $25 \mu \mathrm{g} / \mathrm{ml}$ TCPP (B and D) and $50 \mu \mathrm{g} / \mathrm{ml}$ TCPP (E): the central nervous system, comprising the sensory vesicle (SV), the motor ganglion (MG) and the neural tube (NT), is strongly marked. (F-J) Ci-Syn expression in controls ( $F$ and $\mathrm{H}$ ) and larvae developed in 25 $\mu \mathrm{g} / \mathrm{ml} \mathrm{TCPP}$ ( $\mathrm{G}$ and $\mathrm{I}$ ) and $50 \mu \mathrm{g} / \mathrm{ml}$ TCPP $(\mathrm{J})$. (K-M) Ci-TH expression in control (K) and larvae exposed to TCPP ( $L$ and $M)$. Scale bar: $100 \mu \mathrm{m}$. 